\title{
Evidence-based decision making and covid-19: what a posteriori probability distributions speak
}

\author{
Sudhir Bhandari ${ }^{1}$, Ajit Singh Shaktawat ${ }^{1}$, Amit Tak $^{2^{\star}}$, Jyotsna Shukla ${ }^{3}$, Bhoopendra Patel ${ }^{4}$, Sanjay \\ Singhal ${ }^{3}$, Jitentdra Gupta ${ }^{3}$, Shivankan Kakkar ${ }^{5}$, Amitabh Dube ${ }^{3}$, Sunita Dia ${ }^{6}$, Mahendra Dia ${ }^{7}$, Todd \\ C. Wehner ${ }^{7}$
}

\begin{abstract}
Background: In the absence of any pharmaceutical interventions, the management of the COVID-19 pandemic is based on public health measures. The present study fosters evidence-based decision making by estimating various "a posteriori probability distributions" from COVID-19 patients.

Methods: In this retrospective observational study, 987 RT-PCR positive COVID-19 patients from SMS Medical College, Jaipur, India, were enrolled after approval of the institutional ethics committee. The data regarding age, gender, and outcome were collected. The univariate and bivariate distributions of COVID-19 cases with respect to age, gender, and outcome were estimated. The age distribution of COVID-19 cases was compared with the general population's age distribution using the goodness of fit $\chi^{2}$ test. The independence of attributes in bivariate distributions was evaluated using the chi-square test for independence.

Results: The age group '25-29' has shown highest probability of COVID-19 cases (P [25-29] = 0.14, 95\% CI: 0.12$0.16)$. The men $(\mathrm{P}[\mathrm{Male}]=0.62,95 \% \mathrm{Cl}: 0.59-0.65)$ were dominant sufferers. The most common outcome was recovery $(P[$ Recovered $]=0.79,95 \% \mathrm{Cl}: 0.76-0.81)$ followed by admitted cases $(P[$ Active $]=0.13,95 \% \mathrm{Cl}: 0.11-0.15)$ and death $(P[D e a t h]=0.08,95 \% \mathrm{Cl}: 0.06-0.10)$. The age distribution of COVID-19 cases differs significantly from the age distribution of the general population $\left(\chi^{2}=399.04, P<0.001\right)$. The bivariate distribution of COVID-19 across age and outcome was not independent $\left(\chi^{2}=106.21\right.$, df $\left.=32, P<0.001\right)$.

Conclusion: The knowledge of disease frequency patterns helps in the optimum allocation of limited resources and manpower. The study provides information to various epidemiological models for further analysis.
\end{abstract}

Keywords: COVID-19, a posteriori Probability Distributions, Epidemiology, Evidence-Based Decision Making, Public Health, SARS CoV-2, India

\section{Background}

According to the World Health Organization report, 8,061,550 confirmed cases and 440,290 confirmed deaths due to coronavirus disease-19 (COVID-19) were recorded by 18 June 2020 across 216 countries globally [1]. In the absence of a vaccine, disease pandemic control includes public health measures such as lockdown and social distancing. The effectiveness of social distancing and the duration of lockdown was investigated using various mathematical models. "Mathematical models are a simplified representation of how infection spreads across a population over time" [2]. Several

*Correspondence: dramitttak@gmail.com

${ }^{2}$ National Centre of Disease Informatics and Research, Indian Council of Medical Research, Bengaluru, Karnataka, India

Full list of author information is available at the end of the article epidemiological models, such as the "mutually exclusive compartments SIR" model (Susceptible, Infectious, or Recovered), used structured age data and social contact matrices to study the progress of the COVID-19 epidemic [3].

Implementation of scientific evidence in making management decisions, developing policies and programs is the essence of evidence-based decision making [4]. A long time has been elapsed since the pandemic's commencement, and a considerable amount of data has been available. The information can be extracted from this data in the form of 'a posterior probability distributions". These distributions generate scientific evidence for further decision making [5]. The pattern of disease frequency distributions in a community is a function of cultural habits and social contacts. The lesser frequency of occurrence of COVID-19 in children might be due to their having fewer outdoor activities and less international travel [6]. 
Furthermore, the effects of public health measures such as lockdown, social distancing, and personal protective measures are reflected in the probability distributions. The probability distributions of various predictors of mortality risk, such as random blood sugar overages, reveals causes of mortality [7]. The present study's objective is the estimation of probabilities for univariate and bivariate distributions of COVID-19 cases over different ages and genders, as observed in patients attending the tertiary care hospitals in Rajasthan.

\section{Methods}

In this hospital-based retrospective observational study, 987 real-time RT PCR, SARS CoV-2 positive cases from SMS Medical College and Hospital, Jaipur, Rajasthan, India, were enrolled. Among the patients, 129 were admitted, 80 had died and, 778 had recovered from COVID-19.

\section{Data Collection}

The age, gender, and outcome data were recorded from the case sheets of the patients. The age distribution of population and age-specific mortality rates were sourced from the government of India repository [8]. Observations were excluded if there were missing data of age, gender, or mortality.

\section{Data analysis procedure}

The univariate discrete probability distributions of age, gender, and outcome were estimated. P[Death], expressed as a percent, is also known as the case fatality rate [9]. The bivariate discrete probability distribution of age and gender, age and outcome, and gender and outcome were also estimated. The conditional probability distributions of $\mathrm{P}$ [Age | Outcome], P [Outcome | Age], P [Age | Gender], P [Gender | Age], P [Gender | Outcome] and $\mathrm{P}$ [Outcome $\mid$ Gender] were obtained using the law of conditional probability: $P[C \mid D]=P[C \cap D] / P[D]$

Where $\mathrm{P}[\mathrm{C} \mid \mathrm{D}]$ is the conditional probability of occurrence of event $\mathrm{C}$ when event $\mathrm{D}$ has already occurred, $\mathrm{P}[\mathrm{C} \cap \mathrm{D}]$ is the probability of occurrence of event $\mathrm{C}$ and $\mathrm{D}$ simultaneously, and $\mathrm{P}[\mathrm{D}]$ is the probability of occurrence of event $\mathrm{D}$ [5]. The age distribution of COVID-19 was compared with the general age distribution. Comparisons were also made for means of age between various levels of gender and outcome. Finally, we compared the outcome among various levels of gender and age groups.

\section{Statistical analysis}

The quantitative variables were expressed as mean and standard deviation, estimates were expressed as 95\% confidence intervals, and comparison was performed using a two-tailed Student t-test. The qualitative variables were expressed as proportions and compared with the chi-square test. The goodness of fit chi-square test was used to test distributions. The statistical level of significance was considered at 5\%. The statistical analyses were done using JASP software [10] and MATLAB 2016a [11].

\section{Results}

The univariate probability distribution of age ( $\mathrm{P}$ [Age]) of coronavirus disease-19 cases has showed maximum probability in the '25-29' age group followed by the ' $30-34$ ' age group and there was a minimum probability in the ' $75-79$ ' age group. The occurrence of COVID-19 cases across age was significantly different $\left(\chi^{2}=411.53, \mathrm{df}=16, P<0.001\right.$ ) (Figure 1 and Table $1)$.

Table 1 Shows the univariate probability distribution of age in COVID-19 patients with $95 \%$ confidence intervals

\begin{tabular}{llll}
\hline Age & P [Age] & \multicolumn{2}{l}{$95 \%$ CI } \\
\cline { 3 - 4 } & & LL & UL \\
\hline $0-4$ & 0.024 & 0.016 & 0.036 \\
$5-9$ & 0.021 & 0.013 & 0.032 \\
$10-14$ & 0.034 & 0.024 & 0.048 \\
$15-19$ & 0.055 & 0.041 & 0.071 \\
$20-24$ & 0.108 & 0.09 & 0.129 \\
$25-29$ & 0.142 & 0.121 & 0.165 \\
$30-34$ & 0.121 & 0.101 & 0.143 \\
$35-39$ & 0.082 & 0.066 & 0.101 \\
$40-44$ & 0.09 & 0.073 & 0.11 \\
$45-49$ & 0.057 & 0.043 & 0.073 \\
$50-54$ & 0.057 & 0.043 & 0.073 \\
$55-59$ & 0.062 & 0.048 & 0.079 \\
$60-64$ & 0.07 & 0.055 & 0.088 \\
$65-69$ & 0.031 & 0.021 & 0.044 \\
$70-74$ & 0.019 & 0.012 & 0.03 \\
$75-79$ & 0.012 & 0.006 & 0.021 \\
80 and Above & 0.014 & 0.008 & 0.024 \\
\hline
\end{tabular}

The age distribution of COVID-19 cases differed significantly with age distribution of the population $\left(\chi^{2}=399.04, P<0.001\right)$ (Figure 2). The probability of men $(\mathrm{P}[\mathrm{Male}]=0.62,95 \% \mathrm{CI}$ : 0.59-0.65) suffering from COVID-19 was higher than for women (P [Female] $=0.38$, 95\% CI: 0.35-0.41) (Figure 3 Panel A and Table 2).

Table 2 Shows univariate probability distribution of gender in COVID-19 patients with a 95\% confidence interval.

\begin{tabular}{llll}
\hline Gender & $\mathrm{P}[$ Gender $]$ & \multicolumn{3}{c}{$95 \% \mathrm{CI}$} \\
& & $\mathrm{LL}$ & $\mathrm{UL}$ \\
\hline Female & 0.38 & 0.35 & 0.41 \\
Male & 0.62 & 0.59 & 0.65 \\
\hline
\end{tabular}

The probability of recovered cases $(\mathrm{P}$ [Recovered] $=0.79$, 95\%CI: $0.76-0.81)$ was higher than for death cases (P [Death] $=0.08,95 \% \mathrm{CI}: 0.06-0.10)$ or admitted cases $(\mathrm{P}$ [Active $]=0.13$, 95\% CI: $0.11-0.15$ ) (Figure 3 Panel B and Table 3).

Table 3 Shows univariate discrete probability distribution of outcome with a $95 \%$ confidence interval.

\begin{tabular}{llll}
\hline Outcome & P [Outcome] & 95\% CI \\
& & LL & UL \\
\hline Recovered & 0.79 & 0.76 & 0.81 \\
Death & 0.08 & 0.06 & 0.10 \\
Active & 0.13 & 0.11 & 0.15 \\
\hline
\end{tabular}

The bivariate probability distribution of age and gender showed males in the '25-29' age group constituted maximum cases of COVID-19 (Table 4). The conditional probability of age for both genders (P [Age | Male] and P [Age | Female]) was highest in the '25-29' age group (Figure 4 Panel A and Panel B). The distribution of COVID-19 cases across age and gender was independent $\left(\chi^{2}=21.30, \mathrm{df}=16, P=0.17\right)$. 
Table 4 Bivariate probability distribution of age and gender (N $=987)$. The age and gender are independent attributes $\left(\chi^{2}\right.$ $=21.30, \mathrm{df}=16, \mathrm{p}=0.17)$

\begin{tabular}{llll}
\cline { 1 - 2 } Age Group & \multicolumn{2}{c}{ Gender } & \\
\cline { 2 - 3 } & Female & Male & \\
\hline $0-4$ & 0.013 & 0.011 & 0.024 \\
$5-9$ & 0.008 & 0.013 & 0.021 \\
$10-14$ & 0.013 & 0.021 & 0.034 \\
$15-19$ & 0.019 & 0.035 & 0.055 \\
$20-24$ & 0.045 & 0.064 & 0.108 \\
$25-29$ & 0.063 & 0.079 & 0.142 \\
$30-34$ & 0.056 & 0.065 & 0.121 \\
$35-39$ & 0.026 & 0.056 & 0.082 \\
$40-44$ & 0.029 & 0.061 & 0.090 \\
$45-49$ & 0.015 & 0.042 & 0.057 \\
$50-54$ & 0.024 & 0.032 & 0.057 \\
$55-59$ & 0.020 & 0.042 & 0.062 \\
$60-64$ & 0.022 & 0.048 & 0.070 \\
$65-69$ & 0.012 & 0.019 & 0.031 \\
$70-74$ & 0.003 & 0.016 & 0.019 \\
$75-79$ & 0.005 & 0.007 & 0.012 \\
80 and above & 0.004 & 0.010 & 0.014 \\
\hline P[Gender] & $\mathrm{P}[$ Female] & $\mathrm{P}[\mathrm{Male}]$ & Total \\
& $=0.379$ & $=0.621$ & $=1.00$ \\
\hline & & &
\end{tabular}

The distribution of COVID-19 cases across age and outcome was not independent $\left(\chi^{2}=106.21, \mathrm{df}=32, P<0.001\right.$ ) (Figure 5 Panel A). The conditional probability distribution of age for given deaths (P [ Age | Death]) was highest in the '60-64' age group, but the conditional probability for death for a given age (P [ Death $\mid$ Age]) was highest in the '75-79' age group (Figure 5 Panel B and Table 5).

Table 5 Bivariate probability distribution of age and outcome $(\mathrm{N}=987)$. The age and outcome are dependent $\left(\left(\chi^{2}=106.21, \mathrm{df}\right.\right.$ $=32, \mathrm{p}<0.001)$

\begin{tabular}{lllll}
\hline Age Group & \multicolumn{3}{c}{ Outcome } & P [Age] \\
\cline { 2 - 4 } & Recovered & Death & Active & \\
\hline $5-4$ & 0.017 & 0.003 & 0.004 & 0.024 \\
$5-9$ & 0.017 & 0.000 & 0.004 & 0.021 \\
$10-14$ & 0.031 & 0.001 & 0.002 & 0.034 \\
$15-19$ & 0.053 & 0.001 & 0.001 & 0.055 \\
$20-24$ & 0.083 & 0.008 & 0.017 & 0.108 \\
$25-29$ & 0.115 & 0.002 & 0.025 & 0.142 \\
$30-34$ & 0.101 & 0.004 & 0.015 & 0.121 \\
$35-39$ & 0.067 & 0.004 & 0.011 & 0.082 \\
$40-44$ & 0.080 & 0.003 & 0.007 & 0.090 \\
$45-49$ & 0.044 & 0.005 & 0.008 & 0.057 \\
$50-54$ & 0.044 & 0.008 & 0.005 & 0.057 \\
$55-59$ & 0.043 & 0.007 & 0.012 & 0.062 \\
$60-64$ & 0.043 & 0.013 & 0.011 & 0.067 \\
$65-69$ & 0.020 & 0.010 & 0.001 & 0.031 \\
$70-74$ & 0.013 & 0.003 & 0.003 & 0.019 \\
$75-79$ & 0.005 & 0.005 & 0.002 & 0.012 \\
80 and above & 0.010 & 0.003 & 0.001 & 0.014 \\
\hline P [Outcome] & $\mathrm{P}[$ Recovered] & $\mathrm{P}[$ Death] & $\mathrm{P}$ [ Active] & Total \\
& $=0.785$ & $=0.081$ & $=0.131$ & $=1.00$ \\
\hline
\end{tabular}

The bivariate probability distribution of gender and outcome showed that the highest proportion of coronavirus cases were male and recovered (Table 6).

Table 6 Bivariate probability distribution of gender and outcome in COVID-19 patients $(\mathrm{N}=987)$. The gender and outcome attributes are independent $\left(\chi^{2}=0.264, \mathrm{df}=2, \mathrm{p}=0.88\right)$

\begin{tabular}{lllll}
\hline \multirow{2}{*}{ Gender } & \multicolumn{3}{c}{ Outcome } & P [Gender] \\
\cline { 2 - 4 } & Recovered & Death & Active & \\
\hline Male & 0.302 & 0.029 & 0.048 & $\begin{array}{l}\text { P [Male] } \\
=0.379\end{array}$ \\
Female & 0.486 & 0.052 & 0.083 & $\begin{array}{l}\text { P [Female }] \\
=0.621\end{array}$ \\
\hline P[Outcome] & $\begin{array}{l}\text { P[Recovered] } \\
\text { = } 0.788\end{array}$ & $\begin{array}{l}\text { P [Death] } \\
=0.081\end{array}$ & $\begin{array}{l}\text { P [Active }] \\
=0.131\end{array}$ & 1.00 \\
\hline
\end{tabular}

The distribution of COVID-19 cases across gender and outcome was independent $\left(\chi^{2}=0.264\right.$, df $=2, P=0.88$ ). The conditional probabilities for males for a given outcome were higher than for females (Figure 6 Panel A-C). The conditional probabilities of outcome for a given gender were higher for recovered cases, followed by active cases and death. (Figure 7, Panel A-C).

\section{Discussion}

Management of the COVID-19 pandemic with limited resources and human resources is challenging for public health authorities. The knowledge of disease patterns helps in decision making as well as for the optimum allocation of resources. The observed disease patterns are affected by biological susceptibility, social contact structure, and cultural habits. The rate of evolution of the epidemic curve in Rajasthan is among the top eight states of India [12]. The mean age of COVID-19 cases was 37.08 years in Rajasthan, which was lower than the mean age-based on 65 research articles [13-15]. The age distribution of the general population of Rajasthan was rightskewed. The mode of the general age distribution curve was the '10-14', age group. In contrast, the mode of the age distribution of COVID-19 cases occurs at the '25-29' age group. This could be explained by the decision of early closure of schools and colleges by the government [16]. The lower frequency of occurrence of COVID-19 in children might result from fewer outdoor activities and less international travel [16]. A national study from China on 2135 pediatric patients showed no significant difference in susceptibility across age groups, although clinical manifestations in children were less severe [17]. The study showed that men constitute more cases of COVID-19, which might be due to higher independence compared to females $[13,18]$. However, the sex ratio of Rajasthan is 926 females per 1000 males [8]. The case fatality rate was $8.1 \%$, which is more than reported for China, i.e., $7.2 \%$ [19]. The higher rate may be due to fewer testing facilities and less contact tracing [20]. In an epidemiological study, COVID19 cases in Maharashtra and New Delhi also showed males' dominance and no association between gender and mortality. The age-specific mortality rate was also high among patients aged $61-70$ years $(19.2 \%), 71-80$ years $(15.8 \%)$, and above 80 years $(13.9 \%)$ as in our study (Figure 5. Panel B, red line graph). The P [Death $\mid$ Age] suggests the probability of death in older age groups was higher, but P [Age |Death] suggests that the need for life-saving equipment was equal in all age groups. 
Similarly, the $\mathrm{P}$ [Active |Age] suggests that hospital beds' requirement was equal over age groups, but $\mathrm{P}$ [Age |Active] suggests that younger age groups occupied more hospital beds.

In the Indian context, we collated a few recommendations

based on estimated a posteriori probability distributions:

Recommendation 1:

The probability of death in elderly group P [ Death $\mid>60$ ] is higher. The people above 60 years should stay at home.

Recommendation 2:

The number of active cases helps in the estimation of requirements for hospital beds and medical equipment. The $\mathrm{P}$ [Age |Active] suggests that younger age groups occupy most hospital beds. P [Death |Age] suggested that younger age groups have a low mortality risk, and management strategies for mild cases might include home isolation. That would free up more hospital beds for the elderly population who are at higher risk of mortality.

Recommendation 3:

The case fatality rate is quite high in our study, possibly due to low COVID-19 testing. Thus, there is a need to increase COVID-19 testing to improve the estimation of the fatality rate.
Furthermore, we recommend the involvement of experts from multiple fields, such as operations research, epidemiology, economics, management, and sociology in policymaking. In addition to above, the psychologists have a key role in managing pandemic of psycho-social disorders contributed by the COVID-19 [21]. This study complains of some limitation. The study estimates probability distributions from the early dataset of COVID-19 cases. As decisions on public health measures like lockdown, contact tracing, and testing guidelines are modified, those, in turn, affect the patterns of disease. Thus, real-time estimations are required and should be adjusted for the confounding effects.

\section{Conclusion}

The patterns of COVID-19 cases and hospital outcomes across age and gender form the basis of evidence-based decision making in the public health domain. Additional demographic, clinical, and laboratory data permit us to determine the magnitude of medical resources and human resources required, along with public health measures.

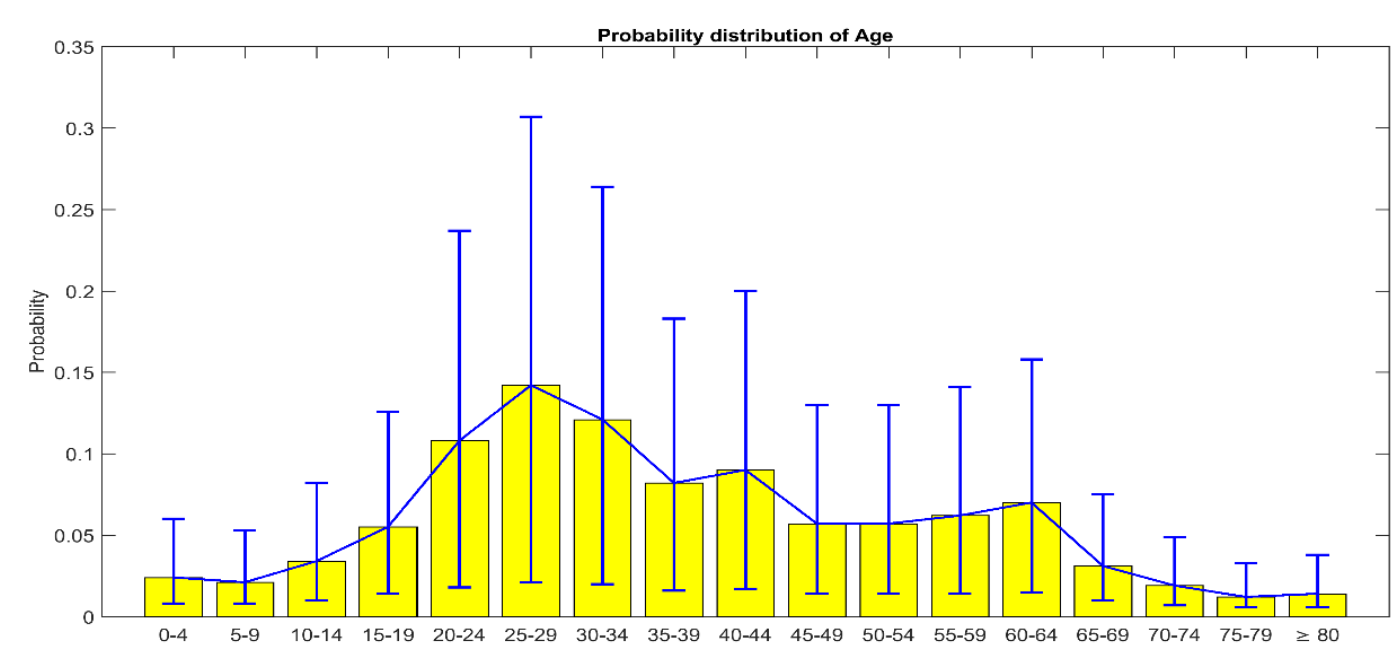

Figure 1 Box plot of univariate discrete age distribution of COVID-19 cases ( $=987$ ) with error bars (blue) at 95\% confidence intervals in the state of Rajasthan

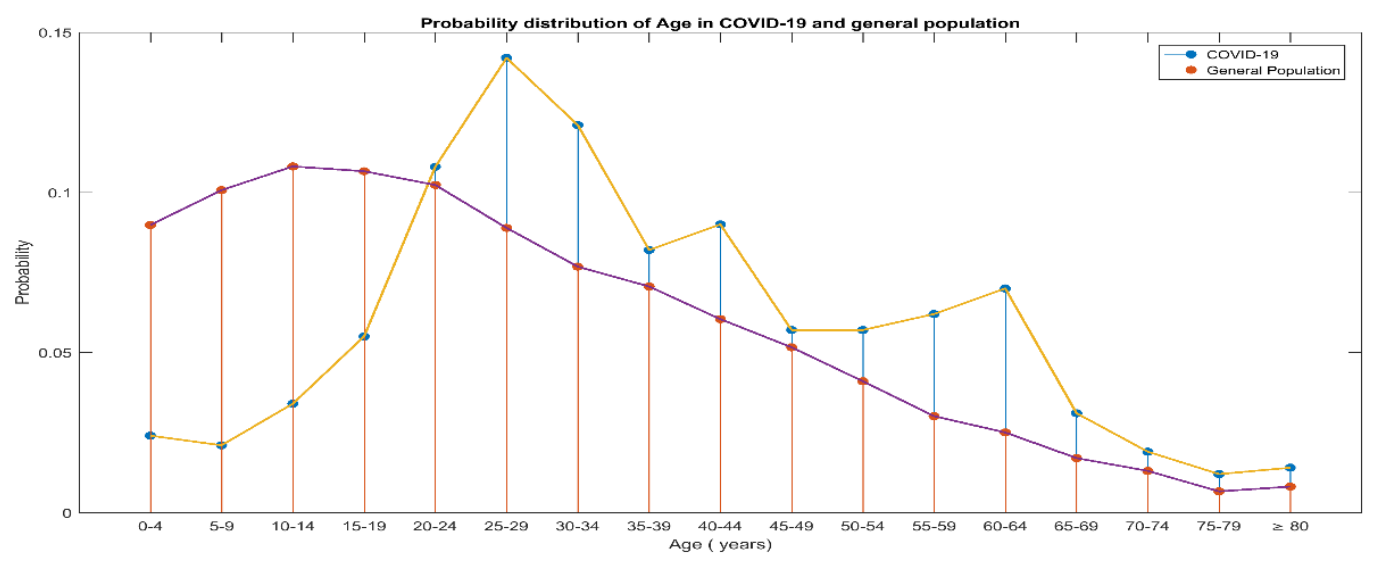

Figure 2 Stem plot of age distribution of observed (blue dots) cases of COVID-19 and expected cases (red dots) in the state of Rajasthan 

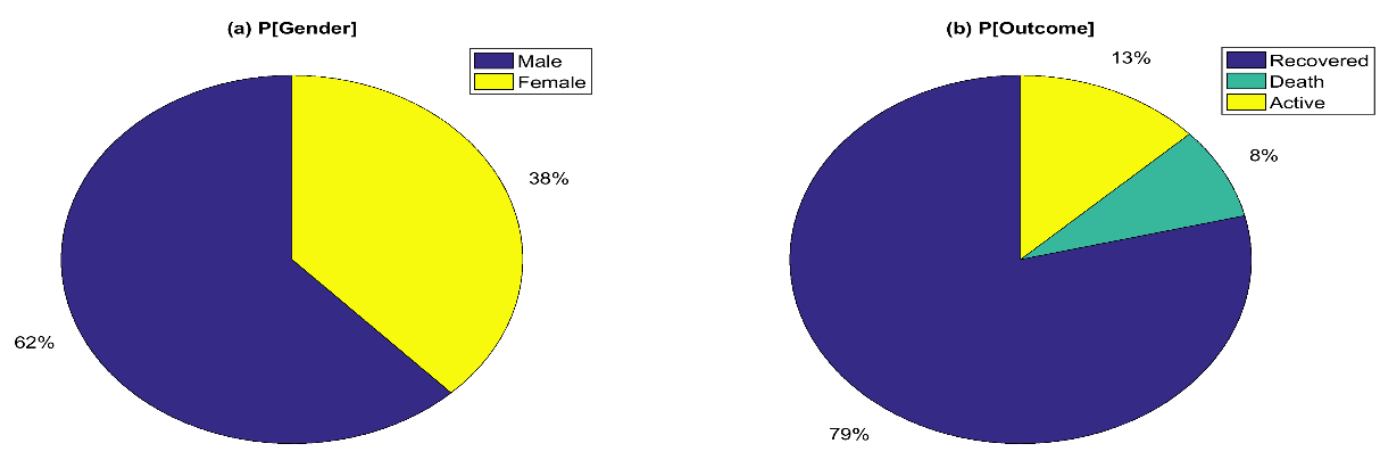

Figure 3 Pie charts of univariate discrete probability distribution of COVID-19 cases (N = 987) in the state of Rajasthan (a) P[Gender] (b) P[Outcome $]$
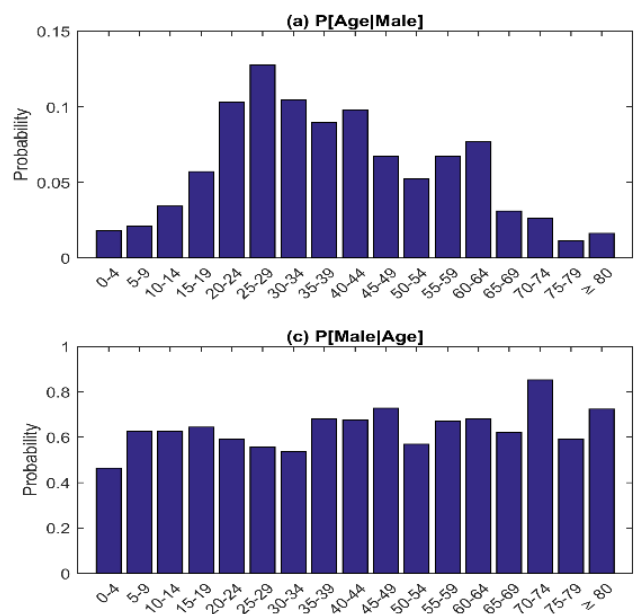

(b) P[Age|Female]

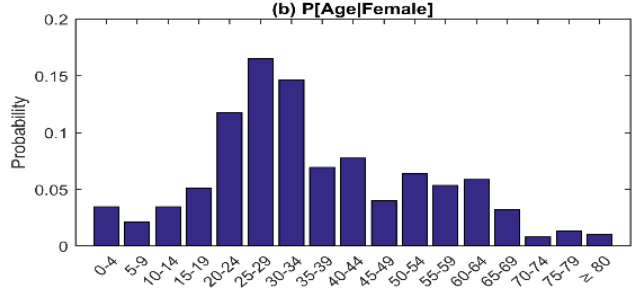

(d) P[Female|Age]

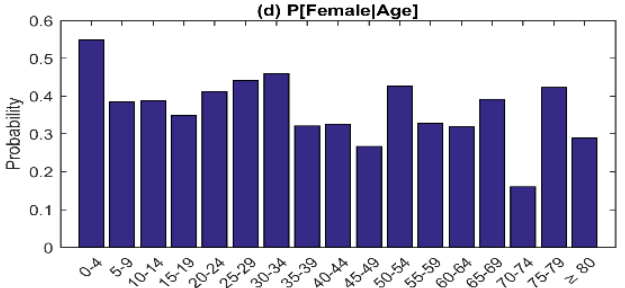

Figure 4 Histograms of conditional probability distributions of age and gender of COVID-19 cases (N = 987) in the state of Rajasthan. Panel A: P [Age| Male], Panel B: P [Age| Female], Panel C: P [Male| Age], and Panel D: P [ Female |Age]
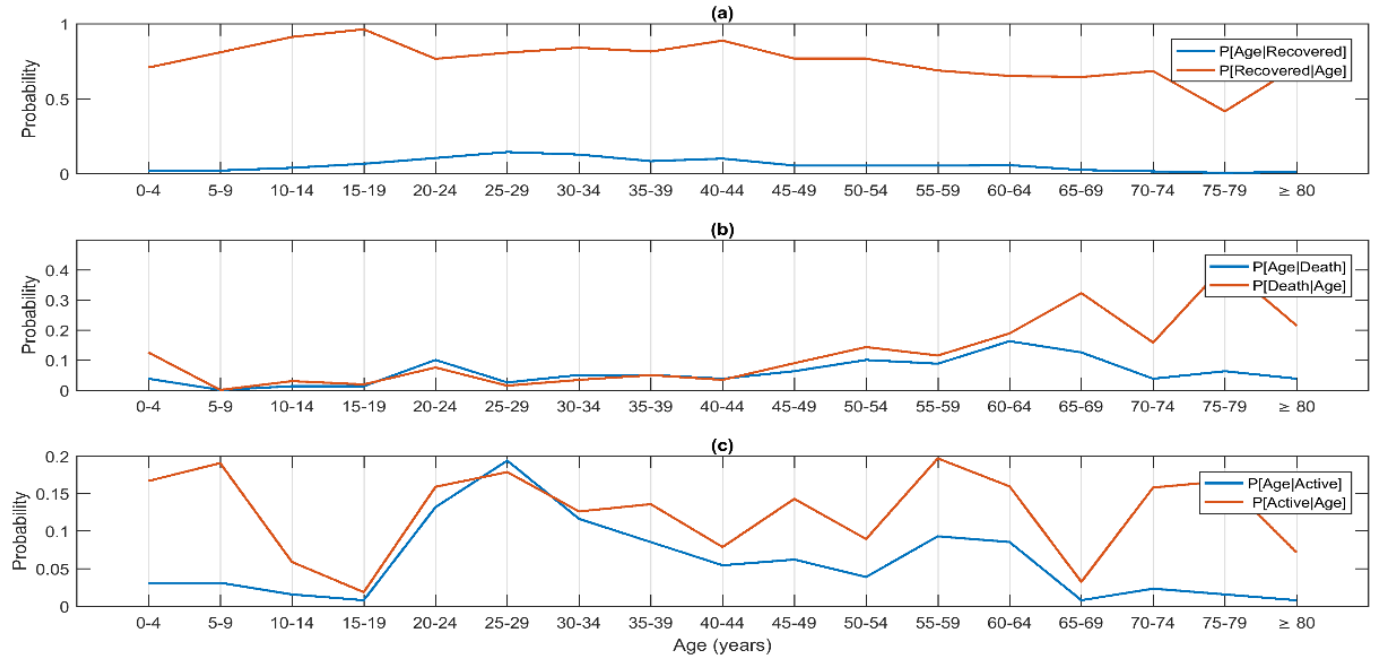

Figure 5 Line plots of conditional probability distributions of age and outcome of COVID-19 cases ( $\mathrm{N}=987$ ) in the state of Rajasthan. Panel A: P [Age| Recovered] (blue line) and P [Recovered| Age] (red line), Panel B: P[Age| Death] (blue line) and P[Death| Age] (red line), and Panel C: P[Age| Active] (blue line) and P[Active| Age] (red line) 

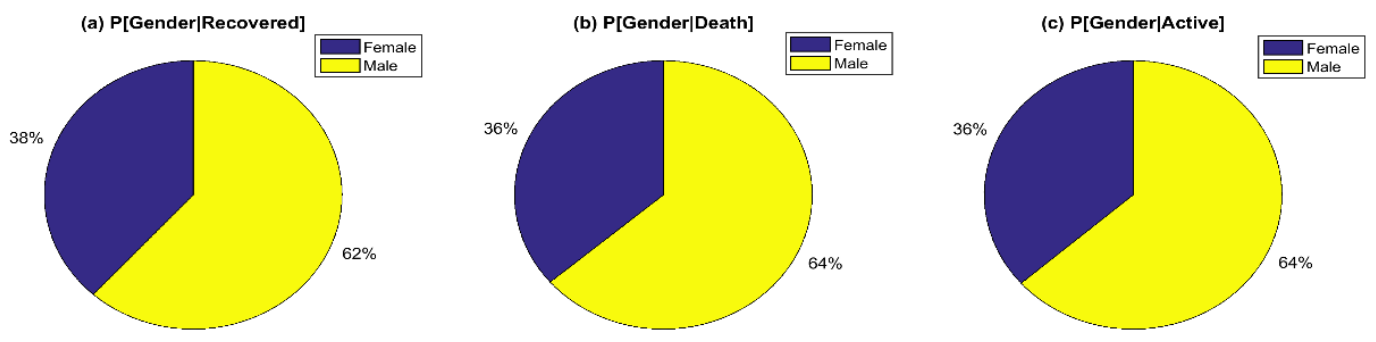

Figure 6 Pie charts of conditional probability distributions of gender for given outcome $(\mathrm{N}=987)$ in the state of Rajasthan. Panel A: P [Gender| Recovered], Panel B: P [Gender| Death] (c), and Panel C: P [Gender| Active]
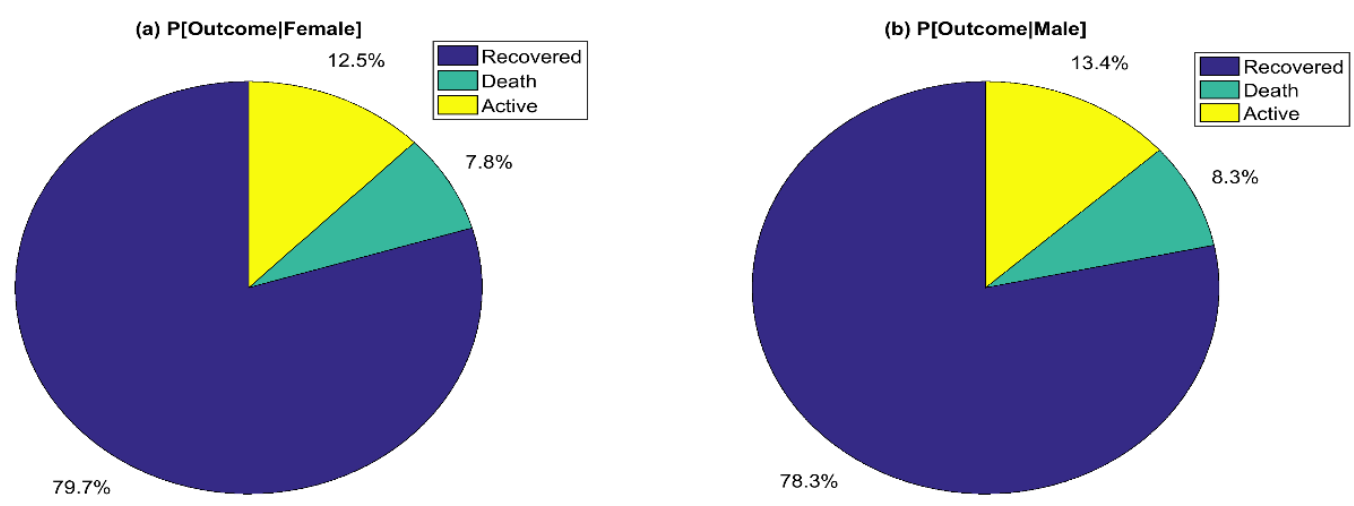

Figure 7 Pie charts of conditional probability distributions of outcome for given gender $(\mathrm{N}=987)$ in the state of Rajasthan. Panel A: P [Outcome| Female], and Panel B: P [Outcome| Male]

\section{Abbreviation}

SIR: Susceptible, Infectious, or Recovered; CI: Confidence Interval; COVID-19: coronavirus Disease-19; P[Age]: Discrete Probability Distribution of Age ; P[Gender]: Discrete Probability Distribution of Gender; P[Outcome]: Discrete Probability Distribution of Outcome; P[Age | Gender]: Conditional Discrete Probability Distribution of Age for a Given Gender; P[ Gender | Age]: Conditional Discrete Probability Distribution of Gender for a Given Age; P[Age | Outcome]: Conditional Discrete Probability Distribution of Age for a Given Outcome ; P[ Outcome | Age]: Conditional Discrete Probability Distribution of Outcome for a Given Age; P[Gender | Outcome]: Conditional Discrete Probability Distribution of Gender for a Given Outcome; P[Outcome | Gender]: Conditional Discrete Probability Distribution of Outcome for a Given Gender; SARS CoV-2: Severe Acute Respiratory Syndrome Coronavirus 2

\section{Declaration}

Acknowledgment

None.

\section{Funding}

The authors received no financial support for their research, authorship, and/or publication of this article.

Availability of data and materials

Data will be available by emailing atifkatib@gmail.com

\section{Authors' contributions}

AT designed the study and coordinated all aspects of the research, including all manuscript preparation steps. He is responsible for studying, designing, writing, reviewing, editing, and approving the manuscript in its final form. SK, AJS, helps in the provision of patients and data collection. SB, JS, and AD provide administrative support, reviewed, and approved the 
manuscript. SS, BP, SK, JG, SD, MD, and TW contributed to drafting the work, writing the manuscript, and reviewed and approved the manuscript. All authors read and approved the final manuscript.

Ethics approval and consent to participate

The authors of this manuscript declare that this scientific work complies with reporting quality, formatting, and reproducibility guidelines set forth by the Declaration of Helsinki. The research has been approved by SMS Medical College, Jaipur Ethics Committee, and the corresponding approval number is 512/MC/EC/2020 dated $6 \mathrm{Jul} 2020$. The retrospective data were used in the study.

\section{Consent for publication}

Not applicable

\section{Competing interest}

The authors declare that they have no competing interests.

\section{Open Access}

This article is distributed under the terms of the Creative Commons Attribution 4.0 International License (http://creativecommons.org/licenses/by/4.0/), which permits unrestricted use, distribution, and reproduction in any medium, provided you give appropriate credit to the original author(s) and the source, provide a link to the Creative Commons license, and indicate if changes were made. The Creative Commons Public Domain Dedication waiver (http://creativecommons.org/publicdomain/zero/1.0/) applies to the data made available in this article, unless otherwise stated.

\section{Author details}

${ }^{1}$ Department of Medicine, SMS Medical College, and Hospitals, Jaipur, Rajasthan, India; ${ }^{2}$ National Centre for Disease Informatics and Research, Indian Council of Medical Research, Bangalore, Karnataka, India. ${ }^{3}$ Department of Physiology, SMS Medical College and Hospitals, Jaipur, Rajasthan, India. ${ }^{4}$ Department of Physiology, Government Medical College, Barmer, Rajasthan, India. ${ }^{5}$ Department of Pharmacology, SMS Medical College and Hospitals, Jaipur, Rajasthan, India. ${ }^{6}$ Department of Rheumatology, Medstar Washington Hospital Center, Washington DC 20010, USA. ${ }^{7}$ Department of Horticultural Science, North Carolina State University, Raleigh, NC 27695-7609, USA.

\section{Article Info}

Received: 10 November 2020

Accepted: 25 December 2020

Published: 31 December 2020

\section{References}

1. World Health Organization, Coronavirus disease- 2019. Available from: https://www.who.int/emergencies/diseases/novelcoronavirus-2019 [Accessed on 18 June 2020]

2. Rodrigues HS. Application of SIR epidemiological model: new trends. Intern. J Appl Math Inf.2016; 10: 92-97.

3. Singh R, Adhikari R. Age-structured impact of social distancing on the COVID-19 epidemic in India.2020; arXiv preprin arXiv:2003.12055.

4. Brownson RC, Gurney JG, Land GH. Evidence-based decision making in public health. J Public Health Manag Pract.1999;5(5):86-97. http://dx.doi.org/10.1097/00124784199909000-00012.
5. Indrayan A, Malhotra RK. Medical biostatistics. 4th ed. In relationships: qualitative dependent, CRC Press, Taylor \& Francis Group, Florida, USA. 2018 pp. 180-182

6. Lee PI, Hu YL, Chen PY, Huang YC, Hsueh PR. Are children less susceptible to COVID-19? J Microbiol Immunol Infect.2020;53(3):371-372. http://dx.doi.org/10.1016/j.jmii.2020.02.011

7. Bhandari S, Shaktawat AS, Tak A, Patel B, Shukla J, Singhal S, et al. Logistic regression analysis to predict mortality risk in COVID-19 patients from routine hematologic parameters. Ibnosina J Med Biomed Sci.2020;12(2):123-9.

8. Census of India 2011, Government of India. Available from: https://censusindia.gov.in/2011-prov-

results/paper2/data_files/Raj/7-popu-10-19.pdf [Accessed on 19 June 2020].

9. Epidemiology group of the new coronavirus pneumonia emergency response mechanism of the Chinese center for disease control and prevention. epidemiological characteristics of the new coronavirus pneumonia[J/OL]. Chinese Journal of Epidemiology2020;41 (2020-0217) http://dx.doi.org/10.3760/cma.j.issn.0254-6450.2020.02.003

10. JASP Team, JASP version 0.12.2 [Computer software] University of Amsterdam, Netherlands; Copyright 2013-2019

11. MATLAB Team, Statistics and Machine Learning Toolbox 10.2, Classification Learner App, MATLAB. version 9.0.0.341360 (R 2016a). Natick, Massachusetts: The MathWorks Inc.

12. Bhandari S, Shaktawat AS, Tak A, Patel B, Gupta K, Gupta J, et al. A multistate ecological study comparing evolution of cumulative cases (trends) in top eight COVID-19 hit Indian states with regression modeling. Int J Acad Med 2020; 6 (2):91-95. http://dx.doi.org/10.4103/IJAM.IJAM_60_20

13. Adhikari SP, Meng S, Wu Y-J, Mao Y-P, Ye R-X, Wang Q-Z, et al. Epidemiology, causes, clinical manifestation and diagnosis, prevention and control of coronavirus disease (COVID-19) during the early outbreak period: a scoping review. Infectious Diseases of Poverty 2020;17: 9(1). http://dx.doi.org/10.1186/s40249-02000646-x

14. Gandhi PA, Kathirvel S. Epidemiological studies on coronavirus disease 2019 pandemic in India: Too little and too late? Med J Armed Forces India. 2020; 76(3): 364-365. http://dx.doi.org/10.1016/j.mjafi.2020.05.003

15. Kakkar S, Bhandari S, Shaktawat A, Sharma R, Dube A, Banerjee $\mathrm{S}$, et al. A preliminary clinico-epidemiological portrayal of COVID-19 pandemic at a premier medical institution of North India. Annals of Thoracic Medicine2020;15(3):146. http://dx.doi.org/10.4103/atm.ATM_182_20

16. Times of India. Available from: https://timesofindia.indiatimes.com/home/education/news/govtannounces-closure-of-all-educational-establishments-across-indiatill-march-31/articleshow/74659627.cms [Accessed on 19 Jun 2020].

17. Dong Y, Mo X, Hu Y, Qi X, Jiang F, Jiang Z, et al. Epidemiology of COVID-19 among children in China. Pediatrics2020; 145 (6): e20200702. https://doi.org/10.1542/peds.2020-0702

18. Ram U, Strohschein L, Gaur K. Gender socialization: differences between male and female youth in India and associations with mental health. International Journal of Population Research 2014; 2014:1-11. http://dx.doi.org/10.1155/2014/357145

19. Chowdhury SD, Oommen AM. Epidemiology of COVID-19. Journal of Digestive Endoscopy2020;11(1):3-7. http://dx.doi.org/10.1055/s-0040-1712187

20. Rajagopalan, Shruti and Tabarrok, Alexander T., Pandemic Policy in Developing Countries: Recommendations for India (April 9, 2020). Mercatus Special Edition Policy Brief, Available at SSRN: https://ssrn.com/abstract=3593011 http://dx.doi.org/10.2139/ssrn.359301

21. Bhandari S, Shaktawat A, Patel B, Dube A, Kakkar S, Tak A Gupta J, Rankawat G. The sequel to COVID-19: the antithesis to life. Journal of Ideas in Health 2020;3(Special1):205-12. https://doi.org/10.47108/jidhealth.Vol3.IssSpecial1.69 